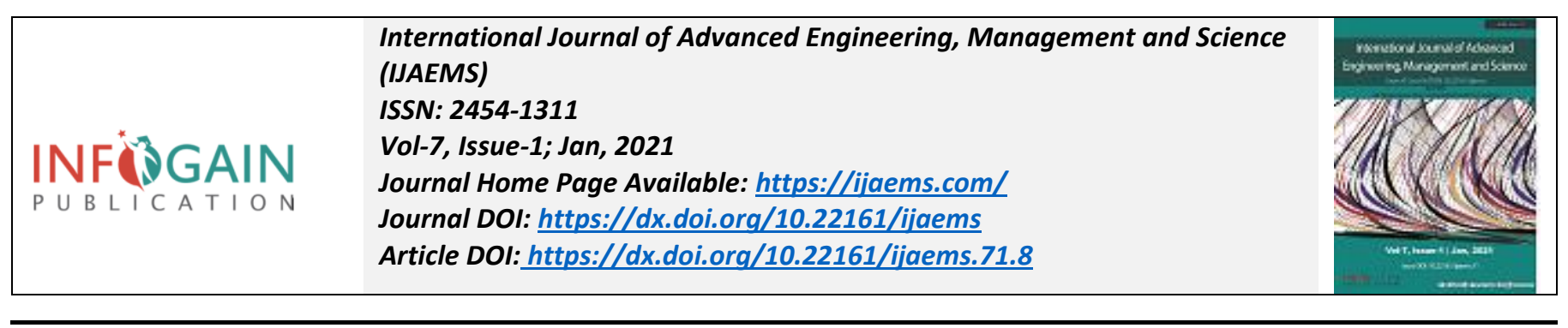

\title{
The Acceptability of System in Assessing the Student's Attendance using Image Processing
}

\author{
Alme B. Maravillas
}

Bohol Island State University Clarin Campus, Philippines

Received: 21 Nov 2020; Received in revised form: 07 Jan 2021; Accepted: 19 Jan 2021; Available online: 29 Jan 2021

(C)2021 The Author(s). Published by Infogain Publication. This is an open access article under the CC BY license

(https://creativecommons.org/licenses/by/4.0/).

\begin{abstract}
Student's attendance is vital in any academic institution as students are the primary stakeholders. There are different means of checking attendance, one of these is automated checking through scanning student's id card using image processing. In Bohol Island State UniversityClarin, there is a system that asses the student's attendance. It is a system that automatically counts the number of students who entered in the premises. This system uses image processing to monitor the attendance by scanning the student id card through a live camera. The system automatically identified the faces of the student with their corresponding id numbers. Thus, the purpose of this study is to assess the acceptability level of thesystem in assessing the attendance. The researcher conducted a survey regarding the system's acceptability on the 200 students that were composed of 100 females and 100 males. It was calculated based on the number responses that the overall weighted mean of the system's acceptability in terms of perceived ease of use and perceived usefulness was 4.1 While the overall standard deviation is 0.58 which means the respondents, who rated the system has a unanimous perception of Very Acceptable. With these results, the researcher concluded that the system is easy to use and useful to the institution since it can monitor accurately the number of logs.
\end{abstract}

Keywords_ Image Processing, Student's Attendance, stakeholders.

\section{INTRODUCTION}

Assessing and understanding the acceptance of the system plays an important role. It should be considered as an issue because the results of it will determine the importance and usefulness of the system to the institution. Thus, purpose of this study is to assess the acceptability level of the system in assessing the student's attendance. It will determine if how effective and useful the system in assessing the student's attendance.

At present, BISU Clarin Library uses the traditional manual and paper-based library services especially in the process of student's attendance logging. The students will log on the attendance sheet prepared by staff before entering inside the premises. The students will provide their student's information. Meanwhile, the staffs will individually count and provides a tally based on the reports of the day. Thus, they found it hassle, unreliable and time-consuming process. With these problems, there is a proposed system that solves the current problem. It is systemthat asses the monitoring of the student's attendance automatically. This system is a new way of record management that achieves efficiency and accuracy on student attendance logging. It uses image processing to monitor the number of students that will enter inside the premises. The system automatically counts and identified the number of studentsthrough scanning their student's id in a live camera. To ensure the usefulness and effectiveness of the system in assessing the attendance. 
Therefore, it is important to measure the acceptability of the system.

\subsection{Technology Acceptance Model (TAM)}

The researcher used Technology and Acceptability Model (TAM) which is an information system theory that models how user come to accept and use a technology. The model suggests that when a user presented with a new technology, several factors influenced the decision about how and when they will used it, notably these are: Perceived Usefulness and Perceived Ease of Use as defined by Fred Davis [5]. Perceived usefulness is the "degree to which a person believes that using a system would enhance their job performance"(i.e., by reducing the time to accomplish a task or providing timely information). While, Perceived ease of use is "the degree to which a person believes that using a system would be free from effort".[6]Attitude towards use and behavioral intention to use are the two other construct of TAM. Attitude towards use is the user's evaluation of the desirability of employing a particular information systems application. Behavioral intention to use is a measure of the likelihood a person will employ the application. Meanwhile, the actual usage is the TAM's dependent. [7]

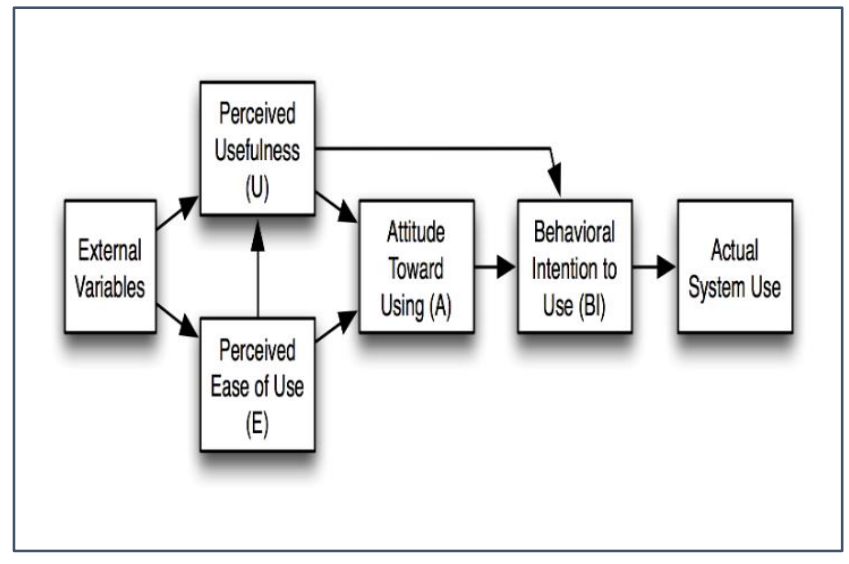

Fig.1: Technology Acceptance Model (TAM)

Based on this figure, it describes that the behavioral intention on system usage is determined by individual's attitude in using the system and perceived usefulness. The behavioral intention is a determinant and a predictor of performing actual behavior. Thus, the individual attitude is highly influence of the system's perceived ease of use and perceived usefulness. [6]

Assessing the acceptability of the system is an important step towards a better understanding on the user's intention in using the system. Technology Acceptance Model (TAM) has been confirmed as a valid model based on the previous researches. [3] This model represents the theoretical framework to explain and predict the attitude towards the usage of the system. Tobing, et. al state that perceived ease of use and perceived usefulness are the two important factors in determining the use of information system as these factors will affect the attitude and intention in using the system. [14]

Moreover, Lee (2006) stated that perceived usefulness and perceived ease of use are the important variables affecting acceptance of the e-learning system. It was showed on the results found in Lee (2006) that showed that perceived ease of use significantly and positively affects perceived usefulness. [10]In the study of Abdullah et. al (2016) in investigating the factors influenced the most commonly used eternal variables such as Self-Efficacy, Subjective Norm, Enjoyment, Computer Anxiety and Experience of TAM on students' Perceived Ease of Use (PEOU) and Perceived Usefulness (PU) in using e-portfolios. It was showed that both perceived ease of use and perceived usefulness affects the behavioral intention on using the e-portfolios system. [1]

Lederer (2000)investigated TAM for work-related tasks with the World Wide Web as the application. The study sought to determine the acceptance of Web technology by users. The results show that the investigation supports TAM.It confirms that use of Web sites depends on the usefulness and ease of use of the site. It also helps the users to understand the predictors of usefulness and ease of use for the Web. [9]Masrom Maslin (2007) on his study on investigating TAM for work-related tasks with e-learning. The author uses TAM as the basisfor hypothesizing the effects of such variables on the use of e-learning as the application. The result shows that the student acceptance of e-learning technology has supported TAM. Results showed that perceived usefulness is more important in determining intention to use than attitude toward using. In agreement with what TAM postulates, perceived usefulness was found to have a significant influence on students' intention to use the technology, that is, it is in accordance with Davis (1989) who found attitude toward using was at best a partial mediator of the effect of perceived usefulness on intention to use, and that it added little causal explanatory power. [11, 7]

\subsection{Assessing the student attendance (AST) system using image processing}

AST is a system that assess the student's attendance automatically. It uses image processing to detect the faces on the students. Before entering inside the premises, the students must scan their id in the front of the camera that is 
connected to the system. Then the camera will detect the face of the student in the id. After detecting the student id number, it sends an information to the SQL database for the verification whether the student is enrolled or not. Then, it will send a notification through sound. A separate sound for detected or not detected.

The development of the system is legally based on RA 9470 states that "All public records must be kept with archival value. The state shall give utmost priority for the safeguard, protection and preservation of its public documents and records". [12] Subsequent to this act, it supports the adaptation of keeping and preserving of all the public records such as the record of logs. [8]

The System Development Life Cycle (SDLC) was used in the development of the system. SDLC is a process of creating an information system and the models used in developing the system. It aims to be standardized that defines the entire task required in developing and maintain the software [4].

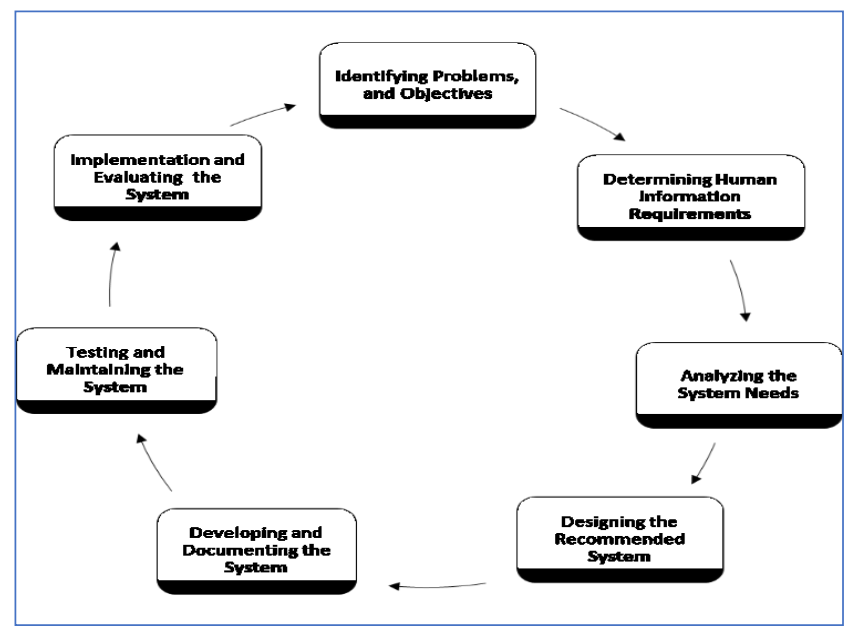

Fig.2: System Development Life Cycle

\section{OBJECTIVE OF THE STUDY}

The main objective of this study is to determine the acceptability of the System in Assessing the Student's Attendance Using Image Processing. This objective was used to look for the opportunities to expand the quality of service as well as the speed of the services in order to achieve the mandates of the institution.

Specifically, this ought to answer the following question:

1. What is the level of the system's acceptability in termsof:

1.1 Perceived ease of use; and

1.2 Perceived usefulness?

\section{METHODOLOGY}

The research design used in this study was descriptive survey method. This method gathers and analyses numerical data to describe the perceptions of the students regarding the system's acceptability. Descriptive survey method is devoted to the gathering of information about prevailing conditions or situations for the purpose of description and interpretation. [2, 13] This type of research method is not simply amassing and tabulating facts but includes proper analyses, interpretation, comparisons, identification of trends and relationship. [2]

The respondents of the study were comprised of 200 students of Bohol Island State University - Clarin campus. The number of respondents were based on random sampling consisting of 100 female students and 100 male students. Before conducting the surveys, the researcher conducted an evaluations and implementation regarding with the system's specification.

In determining the level of acceptability of the system, the researcher uses the TAM's theory by Fred Davis. It is a model that suggest when a user presented with a new technology, several factors influenced the decision about how and when they will used it, notably these are: Perceived Usefulness and Perceived Ease of Use. [5]

The questionnaire contains two parts: Part 1 will deal with system's acceptability in terms of perceived ease of use while part 2 deals with perceived usefulness with the Likertscale namely: Perfectly Acceptable (5), Very Acceptable (4), Acceptable (3), Slightly Acceptable (2) and Not Acceptable (1).

\section{RESULTS AND DISCUSSIONS}

In terms of measuring the system's acceptability, the researcher conducted a survey to the respondents. The respondents are comprising of 200 selected students. The following table shows the level of acceptability of the system in terms of perceived ease of use and perceived usefulness. 
Table 1 Acceptability of the System in terms of Perceived Usefulness

\begin{tabular}{|c|c|c|c|c|}
\hline Item & Questions & SD & Mean & DR \\
\hline 1 & $\begin{array}{l}\text { In the system, it would } \\
\text { enable me to accomplish } \\
\text { the task more quickly and } \\
\text { easier }\end{array}$ & $\begin{array}{c}0.5 \\
6\end{array}$ & 3.9 & VA \\
\hline 2 & $\begin{array}{l}\text { The system generates } \\
\text { complete and exact reports }\end{array}$ & $\begin{array}{c}0.6 \\
2\end{array}$ & 4.2 & VA \\
\hline 3 & $\begin{array}{l}\text { The system calculates the } \\
\text { number of logs } \\
\text { automatically }\end{array}$ & $\begin{array}{c}0.6 \\
7\end{array}$ & 4.4 & PA \\
\hline 4 & $\begin{array}{l}\text { Monitors the number of } \\
\operatorname{logs} \text { accurately. }\end{array}$ & $\begin{array}{c}0.5 \\
7\end{array}$ & 4.1 & VA \\
\hline 5 & $\begin{array}{l}\text { Using the system, it would } \\
\text { enable me to view the logs } \\
\text { by date. }\end{array}$ & $\begin{array}{c}0.6 \\
3\end{array}$ & 4.4 & $\mathrm{PA}$ \\
\hline 6 & $\begin{array}{l}\text { The system is precise and } \\
\text { accurate }\end{array}$ & $\begin{array}{c}0.5 \\
7\end{array}$ & 4.0 & VA \\
\hline
\end{tabular}

Composite Mean: 4.1 VA

Overall SD : 0.60

The table above represents the system's acceptability level in terms of perceived usefulness. Perceived usefulness refers to the degree in which the persons believe that using the system would enhance their job performance. [6] Based on the data gathered, it was found out that the level of the acceptability in terms of perceived ease of use was 4.1 in which it has a descriptive rating of Very Acceptable. The items 3 and 5 has a descriptive rating of Perfectly Acceptable which means the system can calculates the logs automatically and can enable the user to view the logs by date. While the items 1 and 6 has a descriptive rating of Very Acceptable which conveys the system accomplish the task quickly and easier and the system is precise and accurate. Moreover, the items 2 and 4 which is the system generates exact reports and the monitors the logs accurately. The overall standard deviation of the system's acceptability in terms of Perceived Usefulness is of 0.60 which means that the respondents unanimously rated the system as Very Acceptable.
Table 2 Acceptability of the System in terms of Perceived Ease of Use

\begin{tabular}{|c|c|c|c|c|}
\hline Item & Questions & $\mathrm{SD}$ & Mean & DR \\
\hline 1 & The system is easy to use. & 0.56 & 4.0 & VA \\
\hline 2 & $\begin{array}{l}\text { It is easy for me to learn and } \\
\text { manipulate the system. }\end{array}$ & 0.50 & 4.3 & PA \\
\hline 3 & $\begin{array}{l}\text { My interaction with the } \\
\text { system is clear and } \\
\text { understandable. }\end{array}$ & 0.57 & 4.4 & PA \\
\hline 4 & $\begin{array}{l}\text { The system is flexible to } \\
\text { interact with. }\end{array}$ & 0.61 & 4.1 & VA \\
\hline 5 & $\begin{array}{l}\text { The system } \\
\text { reduces/eliminates paper } \\
\text { works and the risk of making } \\
\text { errors while tracking the } \\
\text { attendance of logs }\end{array}$ & 0.63 & 4.6 & PA \\
\hline 6 & The system is user-friendly & 0.50 & 3.41 & VA \\
\hline Con & site Mean: 4.1 & & & \\
\hline Ove & $11 \mathrm{SD}:$ & & & \\
\hline
\end{tabular}

This table shows the result of calculated weighted mean and standard deviation based on the responses of the respondents in terms of perceived ease of use. Perceived ease of use refers to the degree to which the respondents believe that using the system would make their task easier. [6] It was shown on the table that the weighted mean in perceive ease of use was 4.1 which has a descriptive rating of very acceptable. The item 1 has a descriptive rating of 4.0 in which implies that the system is easy to use. The item 2 refers to the question in which the system is easy to learn and manipulate got a descriptive rating of Perfectly Acceptable and a standard deviation rating of 0.50 . The result also showed that the system is clear and understandable (Item 2, mean $4.3 \& 0.50 \mathrm{SD})$ and the system reduces/eliminates the paper works (Item 5, mean $4.6 \&$ SD 0.63). Furthermore, items 3 and 5 got a descriptive rating of Perfectly Acceptable. The overall standard deviation of the system's acceptability in terms of Perceived Ease of Use is of 0.60 which means that the respondents consistently rated the system as Very Acceptable 
Table 3 Consolidation of the Level of Acceptability of the System

\begin{tabular}{|c|c|c|c|c|}
\hline Item & System's Acceptability & SD & Mean & DR \\
\hline 1 & Perceived Usefulness & 0.60 & 4.1 & VA \\
\hline 2 & Perceived Ease of Use & 0.56 & 4.1 & VA \\
\hline \multicolumn{5}{|c|}{ Composite Mean: $4.1 \quad$ VA } \\
\hline Over & 0.58 & & & \\
\hline
\end{tabular}

The table above shows the overall result of the acceptability of the system. It was calculated based on the number responses that the overall weighted mean of the system's acceptability in terms of perceived ease of use and perceived usefulness was 4.1 which has a descriptive rating of Very Acceptable which conveys the system is useful to the institution and easy to use. While the overall standard deviation is 0.58 which means the respondents, who rated the system has a unanimous perception of Very Acceptable.

\section{CONCLUSION}

Based on the survey results, it has supported TAM. The results shown based on the number of responses that the weighted mean is 4.1 in which it has a descriptive rating of Very Acceptable in terms of perceived usefulness. While in terms of perceived ease of use, the weighted mean in perceive ease of use is 4.1 which has a descriptive rating of very acceptable. On the overall acceptability level of the system, the overall weighted mean of the system's acceptability in terms of perceived ease of use and perceived usefulness was 4.1 which has a descriptive rating of Very Acceptable. These results implied that the system is easy to use and useful to the institution.

\section{REFERENCES}

[1] Abdulla, Fazil\& Ward Rupert. (2016). Developing a General Extended Technology Acceptance Model for E-Learning (GETAMEL) by analysing commonly used external factors, Computers in Human Behavior. Retrieved from: https://doi.org/10.1016/j.chb.2015.11.036.

[2] Aggrawal, Y.P. (1990) Statistical methods, concepts, applications and computations. Sterling Publishers Pvt Ltd, New Delhi.

[3] Al-Gahtani, S. S. (2016). Empirical investigation of e-learning acceptance and assimilation: a structural equation model.
Applied Computing and Informatics, 12(1),27e50. Retrieved from: http://dx.doi.org/10.1016/j.aci.2014.09.001.

[4] Introduction to Software Development Life Cycle (2015). Retrieved from: https:// www.subjectcoach.com/tutorials/detail/contents/introductionto-software-development-life-cycle-sdlc

[5] Davis, F. D. (1986). A technology acceptance model for empirically testing new enduser information systems: Theory and result. Doctoral dissertation (pp. 1e291). Sloan School of Management. Massachusetts Institute of Technology. Retrieved from: http://dspace.mit.edu/handle/1721.1/15192.

[6] Davis, F. D., Bagozzi, R. P. \&Warshaw, P. R. (1989). User acceptance of computer technology: a comparison of two theoretical models. Management Science. 35, 8, 982-1003.

[7] Davis,F.D. Perceived usefulness, perceived ease of use, and user acceptance of information technology, MIS Quarterly 3 1989 319-339.

[8] Electronic Commerce Act 2000 (PHI). Retrieve from: https://dilg.gov.ph/issuances/ra/RA-8792-Phil-eCommerceAct-of-2000/4

[9] Lederer, A. L., Maupin, D. J., Sena, M. P., \& Zhuang, Y. (2000). The technology acceptance model and the World Wide Web. Decision Support Systems, 29(3), 269282. doi:10.1016/s0167-9236(00)00076-2

[10] Lee, Y. (2006). An empirical investigation into factors influencing the adoption of an e-learning system. Online Information Review, 30(5), 517e541. http://dx.doi.org/ 10.1108/14684520610706406.

[11] Masrom, M. (2007). Technology Acceptance Model and Elearning. [Online]. Retrieved from: http://eprints.utm.my/5482/1/MaslinMasrom2006_techn.pdf. (Accessed on $27 \mathrm{Jul}$ 2012).

[12] National Archives of the Philippines Act 2007(PHI). Retrieve from: https://www.officialgazette.gov.ph/2007/05/21/republicact-no-9470/

[13] Salaria, N. (2012). Meaning of the term - descriptive survey research method. International Journal of Transformation in Business Management Vol. No.1 Issue No.6

[14] Tobing, Vainny\& Hamzah, Muzaffar \& Sura, Suaini\& Amin, Hanudin. (2008). Assessing the acceptability of Adaptive ELearning System. 5th International Conference on ELearning for Knowledge-Based Society. 